\title{
A Primer on Ebola for Clinicians
}

\author{
Eric Toner, MD; Amesh Adalja, MD, FACP; Thomas Inglesby, MD
}

\section{ABSTRACT}

The size of the world's largest Ebola outbreak now ongoing in West Africa makes clear that further exportation of Ebola virus disease to other parts of the world will remain a real possibility for the indefinite future. Clinicians outside of West Africa, particularly those who work in emergency medicine, critical care, infectious diseases, and infection control, should be familiar with the fundamentals of Ebola virus disease, including its diagnosis, treatment, and control. In this article we provide basic information on the Ebola virus and its epidemiology and microbiology. We also describe previous outbreaks and draw comparisons to the current outbreak with a focus on the public health measures that have controlled past outbreaks. We review the pathophysiology and clinical features of the disease, highlighting diagnosis, treatment, and hospital infection control issues that are relevant to practicing clinicians. We reference official guidance and point out where important uncertainty or controversy exists. (Disaster Med Public Health Preparedness. 2015;9:33-37) Key Words: Ebola, epidemics, public health emergencies

I n March 2014, Ebola virus (EV) was discovered to be the etiologic agent behind an outbreak of a highly lethal disease that had begun in the nation of Guinea in December 2013. ${ }^{1}$ The index patient is thought to have been a 2 -year-old child. ${ }^{1}$ How he was infected is not certain. This was the first known outbreak of Ebola virus disease (EVD) in West Africa. Since that time, the outbreak has escalated to a neverbefore-seen scale, spreading to, and causing worse epidemics in, the bordering nations of Sierra Leone and Liberia. As the outbreak has continued, exportations of the virus to Senegal, Nigeria, and the United States have occurred. ${ }^{2,3}$ Additionally, several individuals infected with Ebola have been evacuated from the region and treated in other countries, including the United States and several European countries. As of October 12, 2014, secondary transmission to at least 2 health care workers outside the epidemic zone has occurred in Spain ${ }^{4}$ and the United States. ${ }^{5}$

Ebola outbreak control measures are relatively low-tech and have been employed with unequivocal success in the 24 preceding - and the one concurrent-Ebola outbreaks. ${ }^{6,7}$ Deploying these outbreak control measures in West Africa, however, has been complicated by several constraining factors that include the lack of local experience with EVD in West Africa, the distrust of governmental authorities by the population, the outbreak epicenter being located on a 3-border region; the level of poverty in these countries; and the inadequate health care infrastructure there. ${ }^{8}$

Another unique aspect of this outbreak is the unprecedented scale of the response and the large mobilization of resources. The World Health Organization, the US government (Centers for Disease Control and Prevention, the National Institutes of Health, the Department of Defense, and the US Agency for International Development), other governments, and many nongovernmental organizations (especially Doctors Without Borders) have been involved in this the largest outbreak response in history. ${ }^{9}$ Also, unlike in prior EVD outbreaks, in the current outbreak unlicensed novel medications, vaccinations, and diagnostics have been made available. ${ }^{10}$

\section{HISTORY OF EBOLA VIRUS DISEASE}

EVD was first described in 1976 after two nearly simultaneous outbreaks in the nations now known as South Sudan and the Democratic Republic of the Congo (DRC; formally known as Zaire). The disease and its causative agent were named for the Ebola River nearby the outbreak in the Congo. These two initial outbreaks were caused by two distinct strains of a novel filovirus that were related to the previously described Marburg virus. ${ }^{11}$ Since that time, sporadic outbreaks have occurred primarily in the nations of Gabon, Uganda, the DRC, and South Sudan. In 1989, a third strain was discovered after a shipment of monkeys from the Philippines to Reston, Virginia, was contaminated with a fatal viral infection. After investigation, a novel strain of Ebola virus was recovered (Ebola Reston) that was found to be nonpathogenic in humans despite causing subclinical infections. ${ }^{12}$ A single case with the fourth strain of Ebola, the Tai Forest strain, in the Cote d'Ivoire has been described. ${ }^{13}$ The fifth and (thus far) 
final strain of Ebola, the Bundibugyo strain, was responsible for an outbreak in Uganda. ${ }^{14}$

\section{EPIDEMIOLOGY AND VIRAL ECOLOGY OF EBOLA}

EVD is a zoonotic disease that spills from an assumed animal reservoir into humans. After extensive searching for the reservoir species, bats are thought to serve that function. ${ }^{15}$ Bats are the most populous mammalian species, are ubiquitous, can travel long distances, and are known to be the reservoir of several human viruses such as rabies, Nipah, SARS, Hendra, and-most significantly-the filovirus Marburg. ${ }^{15}$ However, although bats are assumed to be the reservoir, direct transmission from bats to humans has not been proven and the virus has yet to be isolated from any bat species. ${ }^{15}$ It is thought, therefore, that intermediary animals such as primates and duikers (African antelopes) may also play a role. Typically, outbreaks have been sparked when a bushmeat hunter (or someone with similar wildlife contact) contracts the illness from an intermediary host and then returns to his local village. ${ }^{16}$ Upon developing symptoms, the patient presents to a health care clinic where he may or may not be accurately diagnosed. If health care providers do not use appropriate personal protective equipment and infection control measures, transmission to health care workers may occur. Transmission is also occurring via burial practices that expose individuals to body fluids during preparation of the body. ${ }^{16}$

Blood and other body fluids are the means by which the virus spreads between humans. Airborne spread has not been documented with any Ebola strain that is pathogenic for humans except in a laboratory setting. ${ }^{17}$ Nor has the control of any prior outbreak been hampered by lack of using airborne precautions.

In recent years, it has been shown that pigs can also be infected with Ebola viruses. In a natural setting in the Philippines, the Reston strain has been isolated from pigs. ${ }^{18}$ Experimental studies have since demonstrated that the Zaire strain can also infect pigs and produce a respiratory illnessin contrast to the human presentation, which does not typically involve respiratory symptoms. ${ }^{19}$ Dogs also exhibit evidence of asymptomatic infection with Ebola virus. ${ }^{20}$

\section{MICROBIOLOGY OF EBOLA}

Ebola is a member of the viral family Filoviridae, whose name derives from the filament-like appearance of the viral particle under electron microscopy. It is a negative-sense, enveloped RNA virus with 7 genes. Enveloped viruses tend to be less hardy, unable to survive long in the environment, and are easily inactivated with ordinary detergents. ${ }^{17}$

The surface glycoprotein encoded by the GP gene is the antigenic stimulus for human antibodies and is the target of investigative vaccines. Several genes of EV act in concert to subvert the actions of interferon, thereby allowing unchecked replication of the virus. ${ }^{17}$

\section{HOW EBOLA OUTBREAKS HAVE BEEN STOPPED}

The following measures to control an EVD outbreak are based on characteristics of the virus and its clinical manifestations. It is important that all control measures be accompanied by public health messaging to explain the rationale behind each measure to the general public as well as to health care personnel. $^{21}$

\section{Recognition}

The first step in a response is the recognition that the virus is present. In areas in which the disease is known to occur, such as the DRC, health care providers and the public are attuned to the cardinal symptoms of the disease which, when present, prompt diagnostic testing. However, in areas in which Ebola has not been known to circulate, such as Guinea, disease recognition and public health response may be delayed. Serological studies of those who tested negative for other known pathogens can be helpful to determine whether Ebola had been circulating at low levels prior to recognition. ${ }^{21}$

\section{Isolation}

Once the diagnosis of EVD has been made, steps must be undertaken to prevent further spread of the disease. Patients must be isolated in a manner that prevents exposure to their blood and body fluids (i.e., droplet/contact precautions) with health care workers using the appropriate personal protective equipment (fluid-impervious gowns, gloves, respiratory protection, and eye protection)..$^{21}$

\section{Contact Tracing}

Once a case has been identified, individuals with whom the patient had contact while symptomatic should be determined and located. Each contact should be questioned as to their degree of exposure. Once identified, each contact should be instructed to monitor temperature periodically as well as to record the onset of any symptoms consistent with EVD. If present, such symptoms should prompt immediate isolation and treatment. This period of observation should last 21 days, corresponding to the longest known incubation period of the virus. A person who had contact with an Ebola patient prior to the onset of symptoms in that patient need not be isolated because there is no evidence that patients are contagious before the onset of symptoms. ${ }^{21}$

\section{Safe Burial Practices}

A key component of diminishing an individual's exposure to blood and body fluids includes ensuring that exposure does not occur postmortem. In historical outbreaks, traditional burial practices in which family members of the deceased bathe, embrace, and kiss the body during a funeral ritual have been linked to transmission of the virus. Instructing the population on how to modify burial ritual so as to eliminate blood and body fluid exposure has been difficult in some communities given cultural sensitivities, but this remains essential to extinguishing transmission. ${ }^{21}$ 


\section{PATHOGENESIS}

Because most human cases of EVD have occurred in remote parts of Africa, there is limited direct information on the pathology of the disease in humans. Most of the available information is extrapolated from experimental work in animals including nonhuman primates. EV enters the host through mucous membranes, breaks in the skin (including microabrasions), and punctures. Experimentally, animals can also be infected by inhaled virus-laden aerosols. EV infects and replicates in a wide variety of cells. Initially, the virus targets monocytes, macrophages, and dendritic cells at the site of inoculation. From there, the virus-laden cells are transported through lymphatics to regional lymph nodes and then through the blood to the liver and spleen. From there, the infected cells disseminate throughout the host. The virus can be found in the skin and nearly all body fluids of infected individuals. ${ }^{22} \mathrm{EV}$, like other filoviruses, is cytotoxic and causes necrosis of many different organs through both direct cellular damage and damage to the microvasculature. Cytokines are strongly stimulated and contribute to the sepsis syndrome that characterizes the late stages of the disease. Tissue necrosis factor seems to play an import role in initiating disseminated intravascular coagulation (DIC) ${ }^{23}$

\section{CLINICAL MANIFESTATIONS}

As its classification as a viral hemorrhagic fever implies, fever occurs in the vast majority of EVD cases. On the other hand, bleeding, which is a manifestation of DIC, occurs in a minority of patients. Only $18 \%$ of patients in the current West African epidemic have had any abnormal bleeding. Gastrointestinal symptoms including pain, vomiting, and especially diarrhea are very common. ${ }^{24}$ In some patients the diarrhea can be voluminous and can rival the fluid loss seen in cholera. ${ }^{25}$ Fever and nonspecific symptoms (fatigue, weakness, malaise, anorexia, headache, hiccups, and abdominal pain) typically begin suddenly after an incubation period that averages 8 to 10 days (range, $2-21$ days). ${ }^{26}$ The frequent occurrence of hiccups was one clue that prompted clinicians in Guinea to suspect EVD in the recent outbreak. ${ }^{27}$ Although sore throat can occur, other respiratory symptoms are not common. ${ }^{28}$ At this stage, the disease is often indistinguishable from many other common diseases including, for example, influenza. Some patients progress no further than this and recover. Some patients may develop an erythematous maculopapular rash in the first week. Conjunctival injection is common. Severe watery diarrhea and vomiting tend to occur after about 5 days. The cause of death in the poorly resourced countries in which outbreaks have occurred is often dehydration and electrolyte imbalance. ${ }^{29}$ This would likely be different in a setting of advanced medical care. Later in the clinical course, altered mental status, septic shock, and bleeding may occur and indicate a poor prognosis. When bleeding does occur it can manifest in many ways including petechiae, abnormal bruising, bleeding from puncture sites, or nasal, gastrointestinal, or vaginal bleeding. Fatal cases tend to progress quickly, with death occurring within 6 to 16 days. ${ }^{26}$ In Africa, case fatality rates have ranged from approximately $25 \%$ to $90 \%{ }^{28}$ This variation may be due to differences among the different Ebolavirus strains and the degree of medical care that is available. In the current West African epidemic, 7 of the first 10 patients who have been treated in the United States or Europe have survived ( 5 in the United States [ 1 died], 2 in Germany, 1 in the United Kingdom, 2 in Spain [both died]).

\section{DIAGNOSIS}

An isolated case of EVD may be very difficult to differentiate clinically from other more common diseases endemic to Africa such as malaria, typhoid fever, Lassa fever, meningitis, and cholera. In the United States, unless an epidemiological link is known (for example, by travel history), an early case may be confused with flu, a later case confused with gastroenteritis, and a very late case with sepsis of any cause. In the midst of an epidemic, clinical diagnosis becomes easier. Routine laboratory testing may show a variety of nonspecific abnormalities at various stages of the illness, including lymphopenia, leukocytosis with a left shift, thrombocytopenia, elevated transaminases, and evidence of DIC. ${ }^{26}$ The principal diagnostic test is reverse transcriptase polymerase chain reaction (RT-PCR). Ebola PCR tests are available in many state public health laboratories and at the Centers for Disease Control and Prevention (CDC). Culture of the virus is possible but is not usually clinically useful. IgG and $\operatorname{IgM}$ enzyme-linked immunosorbent assays (ELISAs) are also available in some laboratories. ${ }^{30}$ The IgM ELISA can provide positive results within a few days of infection but offers little benefit over PCR. Serologic assays are useful only in retrospect. It is critically important to remember that blood specimens from patients with EVD may be extremely infectious and thus must be handled accordingly.

\section{TREATMENT}

The mainstay of the treatment of EVD is good supportive care, especially fluid replacement. If the patient can drink, oral rehydration may be adequate. If not, intravenous fluid replacement is needed. The Canadian Critical Care Society recommends Ringer's Lactate as the fluid of choice. The volume of fluid needed will depend on the degree of fluid deficit and ongoing loss. If the patient is hypotensive, an initial bolus of $20 \mathrm{~mL} / \mathrm{kg}$ (repeated as needed) is recommended. ${ }^{31}$ If shock, DIC, or other organ dysfunctions are evident, they should be treated with standard critical care protocols as with any other patient with septic shock. Routine antibiotics are not indicated. Anecdotal reports suggest that the prognosis of EVD can be substantially improved with good supportive care.

There are no licensed specific medications for EVD. Several investigational drugs are just beginning early clinical trials 
and have been used under compassionate use protocols for a small number of patients with EVD. ${ }^{32}$ These include a cocktail of 3 monoclonal antibodies produced by genetically engineered tobacco plants (ZMapp; Mapp Biopharmaceutical, San Diego, CA) ${ }^{33}$ a small interfering RNA (TKM-Ebola; Tekmira, Burnaby, BC, Canada), ${ }^{34}$ an RNA polymerase inhibitor (BCX4430; BioCryst Pharmaceuticals, Durham, NC), ${ }^{35}$ and an anti-sense short chain RNA (AVI 7537; Sarepta Therapeutics, Cambridge, MA). ${ }^{36}$ Whether these drugs are safe or effective is not yet known, because Phase 1 clinical trials have yet to be reported or, in some cases, conducted. Convalescent blood products (whole blood or plasma) from Ebola survivors have also been used in some EVD patients. Whether these therapies have been effective is not known; no controlled clinical trials have been reported. ${ }^{37}$ Brincidofovir (Chimerix, Durham, NC), an as yet unlicensed antiviral drug, was used to treat the first patient in Texas who subsequently died. Although never before used for EVD, the drug has been used in human trials for several other DNA viruses. ${ }^{38}$

\section{BIOSAFETY AND INFECTION CONTROL}

Ebola virus is transmitted primarily by direct contact with body fluids. It is suspected that fomites can be involved as well. CDC guidance recommends standard contact and droplet precautions for routine care of EVD patients in hospitals. ${ }^{39}$ This includes gloves, fluid-resistant gowns, eye protection, masks, and shoe covers. Surfaces should be disinfected. Airborne precautions (N95 respirator or Powered Air Purifying Respirator [PAPR] and negative pressure isolation) should be implemented for aerosol-generating procedures. As with other blood-borne pathogens, virus-laden body fluids aerosolized during vomiting, explosive diarrhea, or medical procedures may be able to transmit the virus as well. For this reason, some experts have advocated a higher level of routine personal protective equipment (PPE) for hospitalized Ebola patients (specifically, N-95s or PAPRs). ${ }^{40}$ Regardless of the type of PPE used, great care should be exercised when removing contaminated garments because it is believed that many health care workers became infected by self-contamination during the PPE removal process. Doctors Without Borders, the organization with the most experience in treating EVD patients, requires its clinical staff working in high-risk zones to adhere to more rigorous PPE standards and infection control procedures than contained in the CDC guidelines, including taping closed all areas of exposed skin, dressing in pairs while putting PPE on to check each other, a specific protocol for doffing PPE, disinfecting PPE with sprayed bleach solutions during PPE removal, and using footbaths to disinfect shoes. ${ }^{41}$

All clinical specimens from EVD patients are highly infectious. Meticulous attention must be paid to proper specimen handling and infection control procedures. Clinical laboratories must be notified in advance before any clinical specimens are sent. Recommendations for laboratory handling of specimens are available at the CDC Web site. ${ }^{42}$

\section{VACCINES}

Several experimental vaccines are in various stages of clinical trials. Whether these vaccines will prove to be safe and effective is not yet known. One vaccine candidate was developed through a collaboration of researchers at the National Institutes of Health and GlaxoSmithKline. It uses an adenovirus vector into which an Ebola gene has been inserted. It is currently in Phase 1 trials. ${ }^{43}$ Another candidate vaccine was developed by the Public Health Agency of Canada and licensed to NewLink Genetics Corp (VSVEBOV). ${ }^{44}$ This vaccine uses a vesicular stomatitis virus as a vector. It is also just entering Phase 1 clinical trials.

\section{CONCLUSION}

The size and ongoing nature of the West African outbreak makes it clear that the further importation of EVD to the United States will remain a real possibility for the indefinite future. American clinicians, particularly those who work in emergency medicine, critical care, infectious diseases, and infection control, should be familiar the fundamentals of EVD including its diagnosis, treatment, and control.

\section{About the Authors}

UPMC Center for Health Security, Baltimore, Maryland (Drs Toner, Adalja, and Inglesby); and University of Pittsburgh Schools of Medicine and Public Health, Pittsburgh, Pennsylvania (Dr Inglesby)

Correspondence and reprint requests to Eric Toner, MD, UPMC Center for Health Security, 621 East Pratt St, Suite 210, Baltimore, MD 21202 (e-mail: etoner@upmc.edu).

Published online: October 17, 2014.

\section{REFERENCES}

1. Blaize S, Pannetier D, Oestereich L, et al. Emergence of Zaire Ebola disease in Guinea. N Engl J Med. 2014;371:1418-1425.

2. Ebola (Ebola Virus Disease). Centers for Disease Control and Prevention Web site. http://www.cdc.gov/vhf/ebola/index.html. Accessed October $11,2014$.

3. Ebola virus disease. World Health Organization Global Alert and Response (GAR) Web site. http://www.who.int/csr/disease/ebola/en/. Accessed October 11, 2014.

4. Ebola case in Spain: ECDC to re-assess transmission risk for Europe. European Centre for Disease Prevention and Control Web site. http:// www.ecdc.europa.eu/en/press/news/_layouts/forms/News_DispForm.aspx? List $=8 \mathrm{db} 7286 \mathrm{c}-\mathrm{fe} 2 \mathrm{~d}-476 \mathrm{c}-9133-18 \mathrm{ff} 4 \mathrm{cb} 1 \mathrm{~b} 568 \mathrm{EID}=1080$. Accessed October 11, 2014.

5. Cohen E, Almasy S, Yan H. Texas nurse who had worn protective gear tests positive for Ebola. CNN website. http://www.cnn.com/2014/10/12/ health/ebola/index.html. Published October 12, 2014. Accessed October 12, 2014.

6. Farrar JJ, Piot P. The Ebola emergency-immediate action, ongoing strategy. $N$ Engl J Med. http://www.nejm.org/doi/full/10.1056/ NEJMe1411471?query=featured_ebola. Published September 23, 2014. Accessed October 11, 2014.

7. Frieden TR, Damon I, Bell BP, et al. Ebola 2014 - new challenges, new global response and responsibility. N Engl J Med. 2014;371:1177-1180.

8. Chan M. Ebola virus disease in West Africa - no early end to the outbreak. N Engl J Med. 2014;377:1183-1185. 
9. Rid A, Emanuel EJ. Why should high-income countries help combat Ebola. JAMA. 2014;312:1297-1298.

10. Joffe S. Evaluating novel therapies during the Ebola epidemic. JAMA. 2014;312:1299-1300.

11. Peters CJ, Peters JW. An introduction to Ebola: the virus and the disease. J Infect Dis. 1999;179(S1):ix-xvi.

12. Miranda MEG, White ME, Dayrit CG, et al. Seroepidemiological study of filovirus related to Ebola in the Philippines. Lancet. 1991;337:425-426.

13. Le Guenno B, Formenty P, Wyers $\mathrm{M}$, et al. Isolation and partial characterization of a new strain of Ebola virus. Lancet. 1995;345:1271-1274.

14. Wamala JF, Lukwago L, Malimbo M, et al. Ebola hemorrhagic fever associated with novel virus strain, Uganda, 2007-2008. Emerg Infect Dis. 2010;16:1087-1092.

15. Kohl C, Kurth A. European bats as carriers of viruses with zoonotic potential. Viruses. 2014;6:3110-3128.

16. Leroy EM, Gonzalez J-P, Baize S. Ebola and Marburg hemorrhagic fever viruses: major scientific advances, but a minor public health threat for Africa. Clin Micro Infect. 2011;17:964-976.

17. Feldmann H, Geisbert TW. Ebola hemorrhagic fever. Lancet. 2011; $377: 849-862$

18. Marsh GA, Haining J, Robinson J, et al. Ebola Reston virus infection of pigs: clinical significance and transmission potential. J Infect Dis. 2011;204(S3):S804-S809.

19. Kobinger GP, Leung A, Neufeld J, et al. Replication, pathogenicity, shedding, and transmission of Zaire ebolavirus in pigs. J Infect Dis. 2011;204:200-208

20. Allela L, Bourry O, Pouillot R, et al. Ebola virus antibody prevalence in dogs and human risk. Emerg Infect Dis. 2005;11:387-390.

21. Clinical management of patients with viral hemorrhagic fever: a pocket guide for the front-line health worker. Geneva, Switzerland: World Health Organization; 2014. http://apps.who.int/iris/bitstream/10665/130883/ 2/WHO_HSE_PED_AIP_14.05.pdf?ua=1. Published March 30, 2014. Accessed October 11, 2014.

22. Feldmann H, Geisbert T. Ebola haemorrhagic fever. Lancet. 2011; 377(9768):849-862.

23. Peters CJ. Marburg and Ebola Virus hemorrhagic fevers. In: Mandell GL, Bennett JE, Dolin R, eds. Principles and Practice of Infectious Diseases, 6th ed. Elsevier; 2005.

24. WHO Ebola Response Team. Ebola virus disease in West Africa-the first 9 months of the epidemic and forward projections. $N$ Eng J Med [published online September 23, 2014]. doi: 10.1056/NEJMoa1411100.

25. Kroll D. Enterovirus D68 and influenza far more dangerous than Ebola in U.S., say top infectious diseases physicians. Forbes Web site. http:// www.forbes.com/sites/davidkroll/2014/10/09/enterovirus-d68-and-influenzafar-more-dangerous-than-ebola-in-u-s-say-top-infectious-diseases-physicians. Published October 9, 2014. Accessed October 11, 2014.

26. Ebola virus disease information for clinicians in U.S. healthcare settings. Centers for Disease Control and Prevention Web site. http://www. cdc.gov/vhf/ebola/hcp/clinician-information-us-healthcare-settings.html. Accessed October 11, 2014.

27. Stern J. Hell in the hot zone. Vanity Fair. October 2014. http://www. vanityfair.com/politics/2014/10/ebola-virus-epidemic-containment. Accessed October 11, 2014.

28. Ebola virus disease fact sheet no. 103. World Health Organization Web site. September 2014. http://www.who.int/mediacentre/factsheets/fs103/en. Accessed October 11, 2014.
29. Lamontagne F, Clément C, Fletcher F, et al. Doing today's work superbly well-treating Ebola with current tools. N Engl J Med [published online September 24, 2014]. doi: 10.1056/NEJMp1411310

30. Ebola (Ebola virus disease). Diagnosis. Centers for Disease Control and Prevention Web site. http://www.cdc.gov/vhf/ebola/diagnosis/. Accessed October 11, 2014

31. Canadian Critical Care Society, Canadian Association of Emergency Physicians, Association of Medical Microbiology \& Infectious Diseases Canada. Ebola clinical care guidelines. Interim report August 19, 2014. http://www.ammi.ca/media/69846/Ebola\%20Clinical\%20Care\%20Guide lines\%202\%20Sep\%202014.pdf. Accessed October 11, 2014.

32. World Health Organization. Background document. Potential Ebola therapies and vaccines. http://www.who.int/csr/disease/ebola/ebola-newinterventions-02-sep-2014.pdf?ua=1. Published September 3, 2014. Accessed October 11, 2014.

33. ZMapp FAQ. Mappbio Web site. http://www.mappbio.com/zmappfaq. pdf. Accessed October 11, 2014.

34. TKM-Ebola. Tekmira Web site. http://www.tekmira.com/pipeline/ tkm-ebola.php. Accessed October 11, 2014.

35. BCX4430. Biocryst Web site. http://www.biocryst.com/bcx_4430. Accessed October 11, 2014.

36. Our pipeline. Sarepta Web site. http://www.sarepta.com/our-pipeline. Accessed October 11, 2014.

37. Experimental therapies: growing interest in the use of whole blood or plasma from recovered Ebola patients (convalescent therapies). Ebola situation assessment. World Health Organization Web site. http:// www.who.int/mediacentre/news/ebola/26-september-2014/en/. Published September 26, 2014. Accessed October 11, 2014.

38. Brincidofovir (CMX001). Chimerix, Inc Web site. http://www.chimerix. com/c/discovery-clinical-trials/brincidofovir.php. Accessed October 11, 2014.

39. Infection prevention and control recommendations for hospitalized patients with known or suspected Ebola virus disease in U.S. hospitals. Centers for Disease Control and Prevention Web site. http://www.cdc.gov/ vhf/ebola/hcp/infection-prevention-and-control-recommendations.html. Updated October 6, 2014. Accessed October 11, 2014.

40. Brosseau L, Jones R. COMMENTARY: Health workers need optimal respiratory protection for Ebola. CIDRAP Web site. http://www.cidrap. umn.edu/news-perspective/2014/09/commentary-health-workers-needoptimal-respiratory-protection-ebola. Published September 17, 2014. Accessed October 11, 2014.

41. Sterk E. Filovirus haemorrhagic fever guideline. Barcelona, Spain: Medcins Sans Frontieres; 2008. http://www.slamviweb.org/es/ebola/ FHFfinal.pdf. Accessed October 11, 2014.

42. Interim guidance for specimen collection, transport, testing, and submission for persons under investigation for Ebola virus disease in the United States. Centers for Disease Control and Prevention Web site. http://www.cdc.gov/vhf/ebola/hcp/interim-guidance-specimen-collectionsubmission-patients-suspected-infection-ebola.html. Updated October 6, 2014. Accessed October 11, 2014

43. Questions and answers. Phase 1 clinical trials of NIAID/GSK investigational Ebola vaccine. National Institute of Allergy and Infectious Diseases webpage. http://www.niaid.nih.gov/news/QA/Pages/EbolaVaxQA.aspx. Published August 28, 2014. Accessed October 11, 2014.

44. Geisbert T, Feldmann H. Recombinant vesicular stomatitis virus-based vaccines against Ebola and Marburg virus infections. J Infect Dis. 2011;204(suppl 3):s1075-s1081. 